\title{
ON REFLECTED AND TRANSMITTED STRESS WAVES AT AN ELASTIC-PLASTIC BOUNDARY
}

\author{
A. S. KHAN The University of Oklahoma
}

\begin{abstract}
A theoretical analysis for the reflected and transmitted waves at an elastic-plastic boundary is presented. The basis of this analysis is the linear elastic wave theory in a hard load-bar and the one-dimensional, strain-rate-independent theory of finite-amplitude plastic waves in a soft specimen. The constitutive relationship during dynamic plastic deformation is an experimentally determined dynamic response function in the soft material. The analysis predicts results that agree very closely with experimental results.
\end{abstract}

\section{INTRODUCTION}

The determination of the elastic and inelastic deformations produced in a body, due to the propagation of finiteamplitude stress waves, is of considerable practical interest to several industries. These finite-amplitude stress waves may be generated during the collision of two bodies, e.g. automobiles. The present paper presents an analytical and an experimental determination of reflected and transmitted waves in a cylindrical specimen when an incident elastic stress wave reaches a discontinuity in the cross-sectional area and in the yield strength of the material. The transmitted part of the incident wave generates several plastic waves if its magnitude is larger than the yield stress of the material.

In the analysis, the linear elastic wave theory in the hard cylindrical specimen (with yield stress higher than the incident stress wave) and a strain-rate-independent nonlinear theory of finite-amplitude waves in the soft specimen. (with a much lower yield stress than the hard specimen) are used. The finite-amplitude wave theory is the one proposed independently by Taylor (1) $\uparrow$, Karman (2), Rakhmatulin, and White and Griffis (3), which predicts that the waves associated with each level of strain will travel at constant speeds. This analysis is similar to the one used by Bell (4). The analytical predictions using the two wave theories mentioned above and some rather simple boundary conditions are shown to agree with measurements of the incident and reflected waves using strain gauges and of the transmitted wave using a diffraction-grating technique (5).

\section{THEORETICAL ANALYSIS}

The situation, for which the following analysis is provided, is shown in Fig. 1. An elastic wave travelling in the hard load-bar is partly reflected and partly transmitted upon its arrival at the interface, which is a discontinuity in the cross-sectional area as well as in the yield stress of the material. The yield stress of the partly hollow and partly solid soft aluminium specimen is much lower than that of the load bar.

For the load-bar, which is never stressed beyond its

The MS. of this paper was received at the Institution on $23 r d$ July 1979 and accepted for publication on 17 th September 1979.

$\uparrow$ References are given in the Appendix.

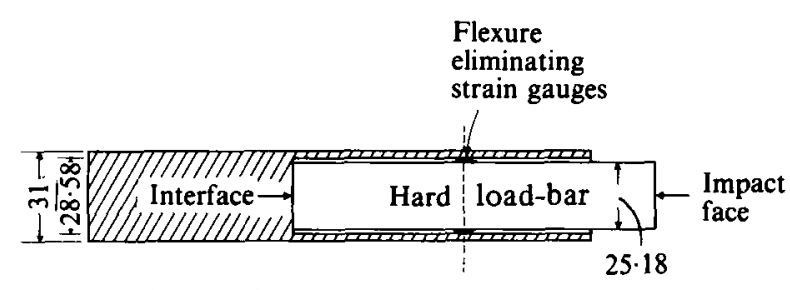

All dimensions are in $\mathrm{mm}$

Fig. 1. Schematic diagram of experiment. Interface was either glued with Eastman Kodak 910 (for glued interface experiments) or lubricated with Dow Corning grease (for lubricated interface experiments)

yield stress, the governing uniaxial linear stress-strain function is

$$
\sigma=E \varepsilon
$$

while for the completely annealed soft specimen, the governing uniaxial stress-strain function, as established by Bell (6), is

$$
\sigma=\beta \varepsilon^{1 / 2}
$$

The experimentally-determined averaged dynamic value of Young's modulus, E, for 2024-T4 aluminium bars at room temperature is $10.2 \times 10^{6} \mathrm{lbf} / \mathrm{in}^{2}$, or $7180 \mathrm{kgf} / \mathrm{mm}^{2}$, while the mass density is $2.53 \times 10^{-4}$ $\mathrm{lbf}-\mathrm{s}^{2} / \mathrm{in}^{4}$, or $2.75 \times 10^{2} \mathrm{kgf}-\mathrm{s}^{2} / \mathrm{m}^{4}$. The calculation of the $E$ was based on the time of arrival of the elastic wave reflected from the free end of the striker bar. The parabola coefficient, $\beta$, for the commercially pure annealed $1100-$ polycrystalline aluminium at a room temperature of $300 \mathrm{~K}$ is $4.57 \times 10^{4} \mathrm{lbf} / \mathrm{in}^{2}$, or $32.14 \mathrm{kgf} / \mathrm{mm}^{2}$.

The stress-particle-velocity relationships referred to an undeformed reference configuration (natural state) and constant wave speeds, as predicted by the elementary linear elastic wave propagation theory of St Venant, in the hard load-bar, are

$$
\sigma=\rho_{0} c_{0} v
$$

and

$$
c_{0}=\left(\frac{E}{\rho_{0}}\right)^{1 / 2}=\frac{X}{t}
$$

Substitution of the parabolic stress-strain function given by equation (2) in the finite-amplitude theory relationships (5) and (6) leads to equations (7) and (8): 


$$
\begin{aligned}
& c_{p}^{2}=\frac{1}{\rho_{0}} \frac{\mathrm{d} \sigma}{\mathrm{d} \varepsilon}=\left(\frac{X}{t}\right)^{2} \\
& v=\int_{0}^{\varepsilon} c_{p} \mathrm{~d} \varepsilon \\
& c_{p}^{2}(\sigma)=\frac{\beta^{2}}{2 \rho_{0} \sigma} \\
& v^{2}=\{\dot{u}(X, t)\}^{2}=\frac{8}{9} \frac{\sigma^{3}}{\rho_{0} \beta^{2}}
\end{aligned}
$$

Combining equations (7) and (8), we obtain a stressparticle-velocity relationship for the nonlinear, finitewave sicuation in the soft specimen, similar to equation (3) for the linear elastic behaviour of the load bar, given by equation (9):

$$
\sigma=\frac{3}{2} \rho_{0} c_{p} v
$$

where $\sigma, \rho_{0}$ and $v$ are stress, mass density and particle velocity, respectively, all referred to the undeformed reference configuration, while $c_{p}(\sigma)$ is the finite-amplitude wave speed, which is constant for any prescribed stress, its value being a function of the stress amplitude. As already explained, the one-dimensional elastic wavefront in the hard bar decomposes into reflected and transmitted wavefronts upon arrival at the interface. Thus, at the elastic-plastic interface, equations (10) and (11) represent the continuity of uniaxial normal force and longitudinal particle velocity, respectively:

$$
\begin{aligned}
& \left(\sigma_{\mathrm{l}}-\sigma_{\mathrm{R}}\right) A_{\mathrm{H}}-\sigma_{\mathrm{T}} A_{\mathrm{T}}=\sigma_{\mathrm{S}} A_{\mathrm{S}} \\
& v_{\mathrm{I}}+v_{\mathrm{R}}=v_{\mathrm{S}}=v_{\mathrm{T}}
\end{aligned}
$$

where $A_{\mathrm{H}}, A_{\mathrm{T}}$ and $A_{\mathrm{S}}$ are the cross-sectional areas of the hard load-bar, the hollow part and the solid part of the specimen, respectively. Subscripts I and R refer respectively to incident and reflected quantities, while $S$ and $T$ refer to transmitted quantities in the solid and hollow portions of the specimen. Using equation (3) for $v_{I}$ and $v_{R}$, and equation (9) for $v_{S}$ and $v_{T}$, equation (11) may be written as

$$
\sigma_{1}+\sigma_{\mathrm{R}}=\sigma_{\mathrm{S}}\left(\frac{2 c_{0}}{3 c_{p \mathrm{~S}}}\right)=\sigma_{\mathrm{T}}\left(\frac{2 c_{0}}{3 c_{p \mathrm{~T}}}\right)
$$

Eliminating $\sigma_{\mathrm{R}}$ between equations (10) and (12) yields a relationship between $\sigma_{\mathrm{T}}$ and $\sigma_{\mathrm{I}}$, given by

$$
2 \sigma_{\mathrm{I}}=\sigma_{\mathrm{T}}\left[\frac{A_{\mathrm{T}}}{A_{\mathrm{H}}}+\left(\frac{\sigma_{\mathrm{S}}}{\sigma_{\mathrm{T}}}\right) \frac{A_{\mathrm{S}}}{A_{\mathrm{H}}}+\frac{2 c_{0}}{3 c_{p \mathrm{r}}}\right]
$$

while using equations (7) and (12) we get

$$
\frac{\sigma_{\mathrm{S}}}{\sigma_{\mathrm{T}}}=\left(\frac{\beta_{\mathrm{s}}}{\beta_{\mathrm{T}}}\right)^{2 / 3}
$$

Therefore, using equations (13) and (14), we can write

$$
2 \sigma_{1}=\sigma_{\mathrm{T}}\left[\frac{2 c_{0}}{3 c_{p \mathrm{~T}}}+\left(\frac{\beta_{\mathrm{S}}}{\beta_{\mathrm{T}}}\right)^{2 / 3} \frac{A_{\mathrm{S}}}{A_{\mathrm{H}}}+\frac{A_{\mathrm{T}}}{A_{\mathrm{H}}}\right]
$$

Similarly, the elimination of $\sigma_{\mathrm{I}}$ and the use of equation (14) gives

$$
2 \sigma_{\mathrm{R}}=\sigma_{\mathrm{T}}\left[\frac{2 c_{0}}{3 c_{p \mathrm{~T}}}-\left(\frac{\beta_{\mathrm{S}}}{\beta_{\mathrm{T}}}\right)^{2 / 3} \frac{A_{\mathrm{S}}}{A_{\mathrm{H}}}-\frac{A_{\mathrm{T}}}{A_{\mathrm{H}}}\right]
$$

By a similar procedure, using equations (10), (12) and (14), we obtain

$$
\begin{aligned}
& 2 \sigma_{\mathrm{I}}=\sigma_{\mathrm{S}}\left[\frac{2 c_{0}}{3 c_{p \mathrm{~S}}}+\left(\frac{\beta_{\mathrm{T}}}{\beta_{\mathrm{S}}}\right)^{2 / 3} \frac{A_{\mathrm{S}}}{A_{\mathrm{H}}}+\frac{A_{\mathrm{T}}}{A_{\mathrm{H}}}\right] \\
& 2 \sigma_{\mathrm{R}}=\sigma_{\mathrm{S}}\left[\frac{2 c_{0}}{3 c_{p \mathrm{~S}}}-\left(\frac{\beta_{\mathrm{T}}}{\beta_{\mathrm{S}}}\right)^{2 / 3} \frac{A_{\mathrm{S}}}{A_{\mathrm{H}}}-\frac{A_{\mathrm{T}}}{A_{\mathrm{H}}}\right]
\end{aligned}
$$

In equations (15) to (18), the second term on the righthand side is small compared with the first term, while the last term is much smaller, since $A_{\mathrm{T}} / A_{\mathrm{H}} \ll 1$.

Now, since the response of the material is the same for dynamic tension and compression (8), then $\beta_{\mathrm{S}}=\beta_{\mathrm{T}}$ $=\beta$ and $c_{p \mathrm{~S}}=c_{p \mathrm{~T}}=c_{p}$ for this case. Therefore, equations (15) and (17) simplify to

$$
\sigma_{\mathrm{S}}=\sigma_{\mathrm{T}}=\beta \varepsilon^{1 / 2}=2 \sigma_{\mathrm{I}} /\left[\frac{2 c_{0}}{3 c_{p}}+\frac{A_{\mathrm{S}}}{A_{\mathrm{H}}}+\frac{A_{\mathrm{T}}}{A_{\mathrm{H}}}\right]
$$

and equations (16) and (18) reduce to

$$
\sigma_{\mathrm{R}}=\sigma_{\mathrm{I}} \frac{\left(2 c_{0} / 3 c_{p}\right)-\left(A_{\mathrm{S}} / A_{\mathrm{H}}\right)-\left(A_{\mathrm{T}} / A_{\mathrm{H}}\right)}{\left(2 c_{0} / 3 c_{p}\right)+\left(A_{\mathrm{S}} / A_{\mathrm{H}}\right)+\left(A_{\mathrm{T}} / A_{\mathrm{H}}\right)}
$$

where $c_{p}$ is the wave speed corresponding to the strain amplitude, $\varepsilon_{\mathrm{T}}\left(=\varepsilon_{\mathrm{S}}\right)$, which corresponds to the incident stress, $\sigma_{1}$, through equation (19). The graphical solution of equations (19) and (20) is achieved by taking a specific strain amplitude (or stress amplitude), calculating the

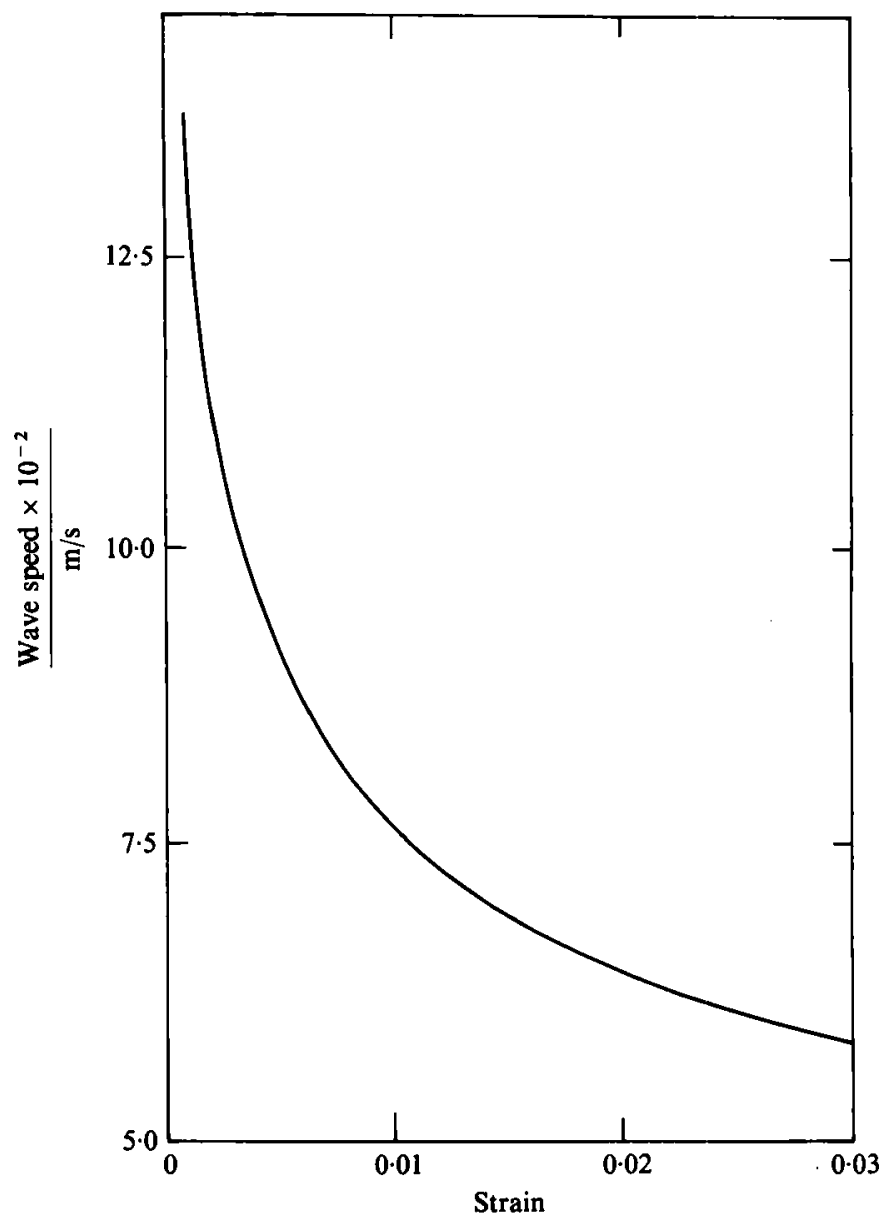

Fig. 2. Calculated wave speed versus strain using parabolic response function 
wave speed corresponding to this value by using equations (7) and (2), and then calculating $\sigma_{1}$ from equation (19). Then, equation (20) gives $\sigma_{\mathrm{R}}$ for those specific values of $\sigma_{\mathrm{I}}$ and $\varepsilon$. Fig. 2 shows the calculated wave speeds for large-amplitude strains, while Fig. 3 is a graphical solution of equations (19) and (20) for $A_{\mathrm{T}} / A_{\mathrm{H}}=0.227$ and $A_{\mathrm{S}} / A_{\mathrm{H}}=1.5187$, the area ratios corresponding to the dimensions of the specimen shown in Fig. 1.

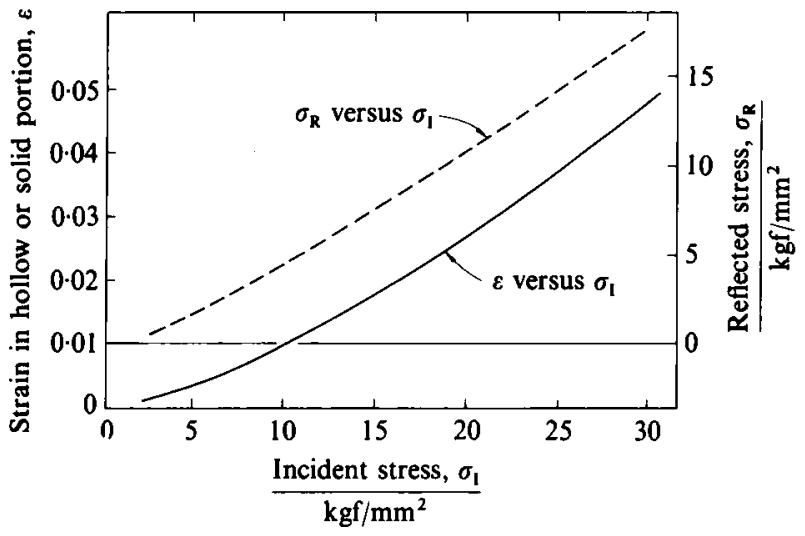

Fig. 3. Graphical solution of equations (19) and (20)

Since the mechanical impedances of the load bar and the striker are the same, as has been stated already, the equivalence of stress and particle velocity at the interface causes a jump in the magnitude of the particle velocity of the specimen equal to half that of the striker. This jump (which also represents the actual particle velocity of the specimen, since the specimen was initially at rest) will be referred to hereafter as the impact velocity. The constant velocity of the striker bar, $2 V_{\text {impact }}$, is determined prior to impact with the aid of velocity wires and an electronic counter. Therefore, by using equation (15), the 'predicted incident stress' is given as

$$
\sigma_{1}=\rho_{0} c_{0} V_{\text {impact }} \text {. }
$$

For this value of predicted incident stress, the 'predicted reflected stress' and 'predicted maximum strain' are found from Fig. 3.

\section{EXPERIMENTAL PROCEDURES}

Details of the experiment, including specimen preparation, have been documented already (7)(8). Here, only a very brief description will be given, to enable an understanding of the boundary conditions. A schematic diagram of the experiment is shown in Fig. 1. An elastic wave is produced in a 2024-T4 or 7075-T6 hard aluminium load-bar by impacting it with an identical striker bar, propelled at constant velocity by a ported-muzzle air-gun. On its arrival at the interface of the load-bar and the soft specimen, this elastic wave induces a compressive wave in the solid portion and a tensile wave in the hollow portion of the specimen. The soft specimen is annealed for two hours at $1100^{\circ} \mathrm{F}$ and furnace-cooled. The dynamic $E$-modulus of the hard load-bar is determined from the measured bar velocity of the elastic waves and the density of the material. A flexure-eliminating combination of two resistance gauges is used to determine the stress history of the load-bar, while the strain history of the soft specimen is determined by using Bell's diffraction-grating technique (5).

\section{EXPERIMENTAL DATA AND DISCUSSION}

The stress histories of the hard load-bar are shown in Figs 4 to 9 . In all cases, the strain gauges were located midway between the impact face and interface of $30.48 \mathrm{~cm}$ long bars, except in test no. 1572 (Fig. 6),

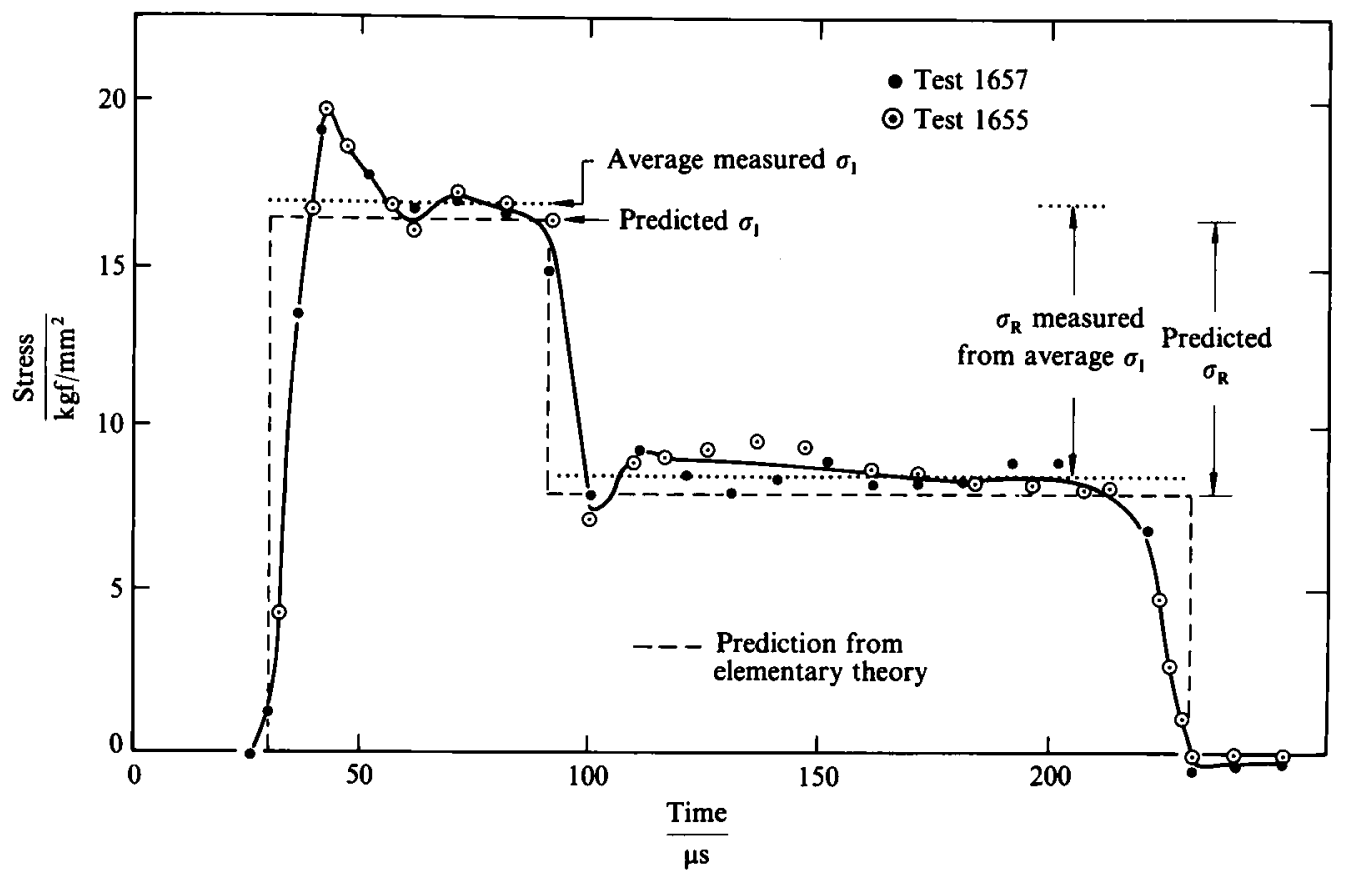

Fig. 4. Stress histories of hard load-bar, measured at $15.24 \mathrm{~cm}$ from impact face using wire resistance gauges. Impact velocities for tests 1655 and 1657 were 11.70 and $10.55 \mathrm{~m} / \mathrm{s}$, respectively. Interface was lubricated in both tests 


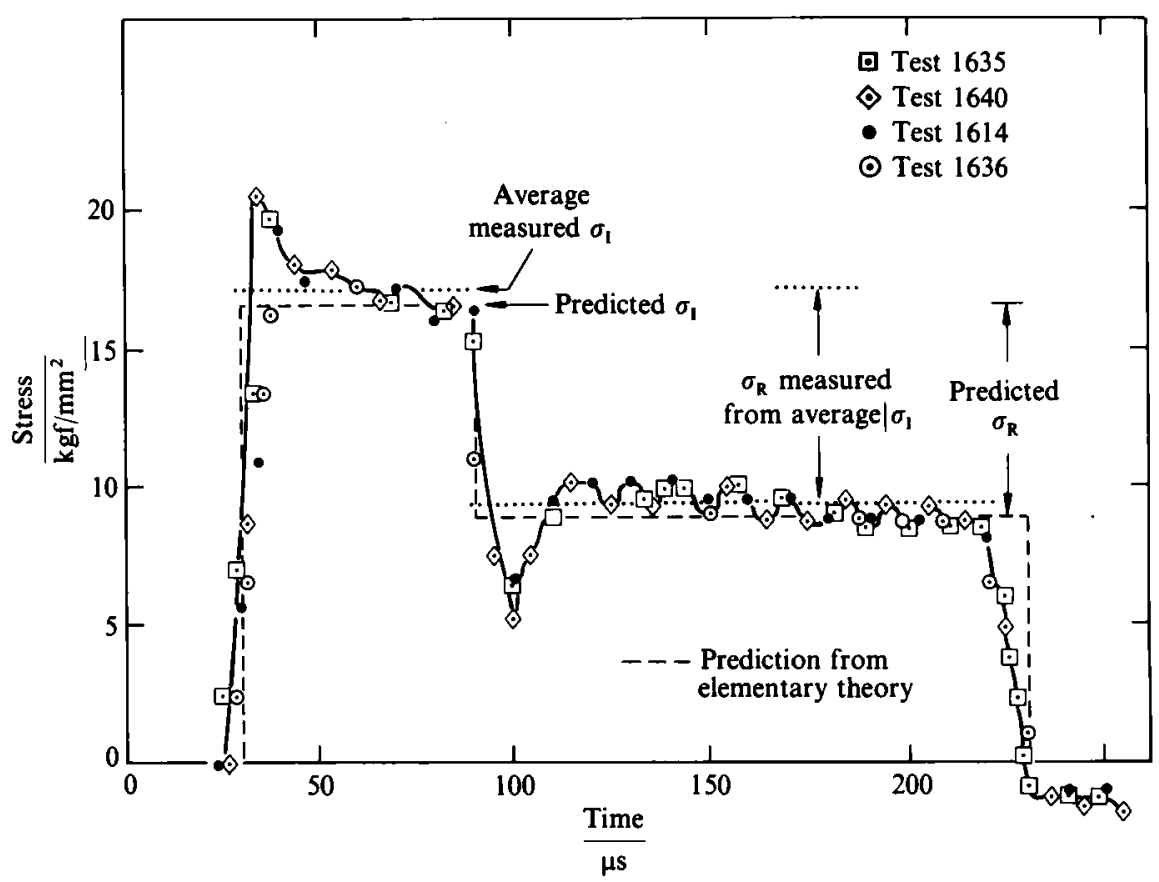

Fig. 5. Four stress histories of hard load-bar, measured at $15.24 \mathrm{~cm}$ from impact face using wire resistance gauges. Impact velocities were $11.08,11.50,11.85$ and $11.42 \mathrm{~m} / \mathrm{s}$. Interface was glued in each test

where these were glued at $20.32 \mathrm{~cm}(8 \mathrm{in})$ from the impact face on a $25.4 \mathrm{~cm}$ long hard load-bar. In test nos 1743 and 1570 , the load and striker bars were made of 7075-T6 aluminium; in all other tests they were made of 2024-T4 aluminium. The impact velocity for each test, or average impact velocity if two or more tests are shown, is given in Figs 4 to 9. For each impact velocity, a predicted incident stress was obtained from equation (21) and then a predicted value for reflected stress was found from Fig. 3. These two predicted values, together with the measured elastic wave speed, were used to obtain a prediction from the elementary theory, as shown by the broken lines in Figs 4 to 9; the agreement between the predicted values and the measurements is seen to be very good. Since the predicted reflected stresses are measured from predicted incident stresses, the slight difference between the predicted and observed reflected stresses in some tests is due to the initial difference between predicted and observed incident stresses. The agreement between predicted and observed reflected stresses is even better if the predicted stress is measured from the observed average incident stress, as can be seen from Figs 4 and 5.

The measured and predicted values of the maximum

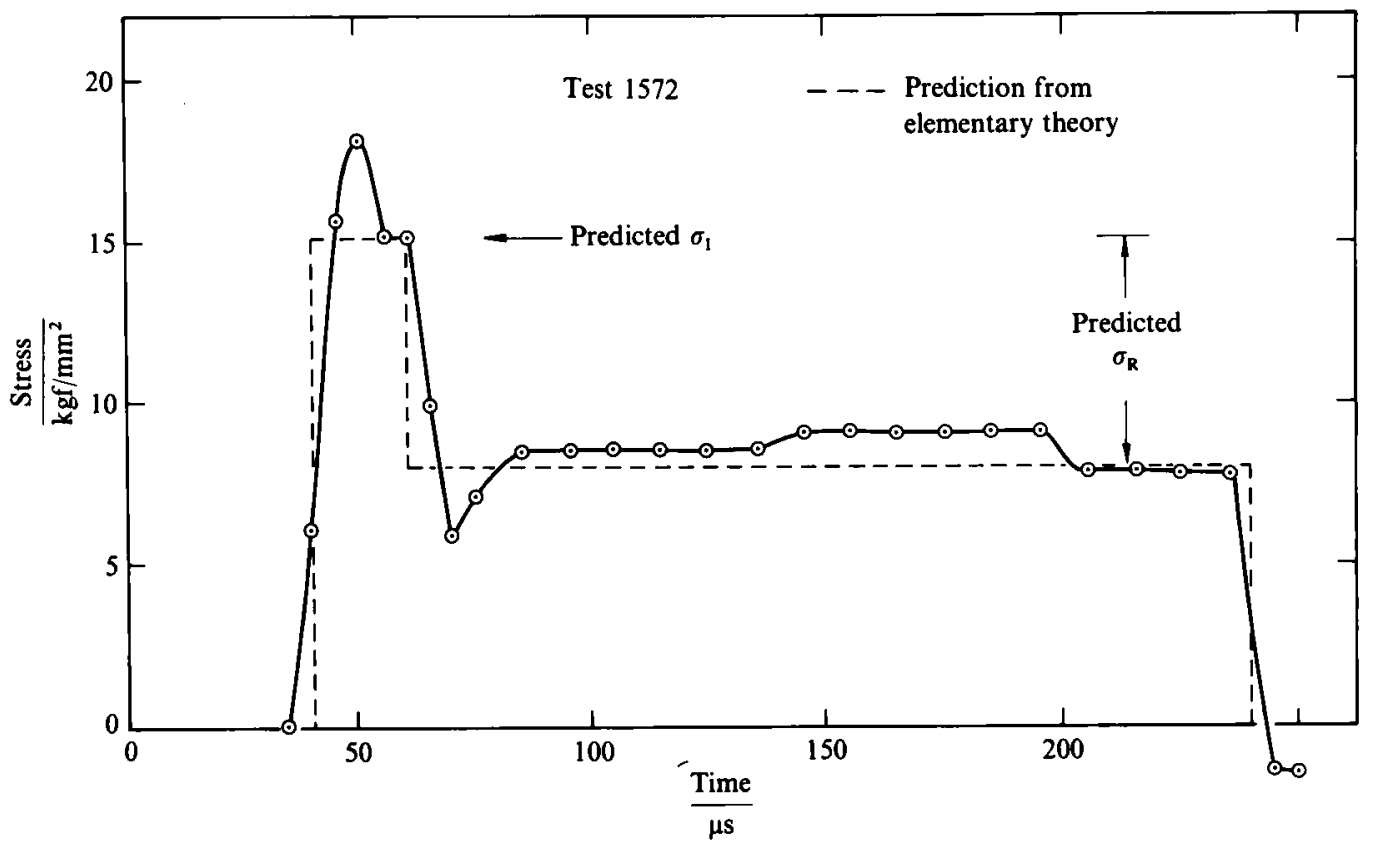

Fig. 6. Stress history of hard load-bar, measured at $20.32 \mathrm{~cm}$ from impact face using wire resistance gauges. Load-bar was only $25.4 \mathrm{~cm}$ long. Interface was glued and impact velocity was $10.38 \mathrm{~m} / \mathrm{s}$. 


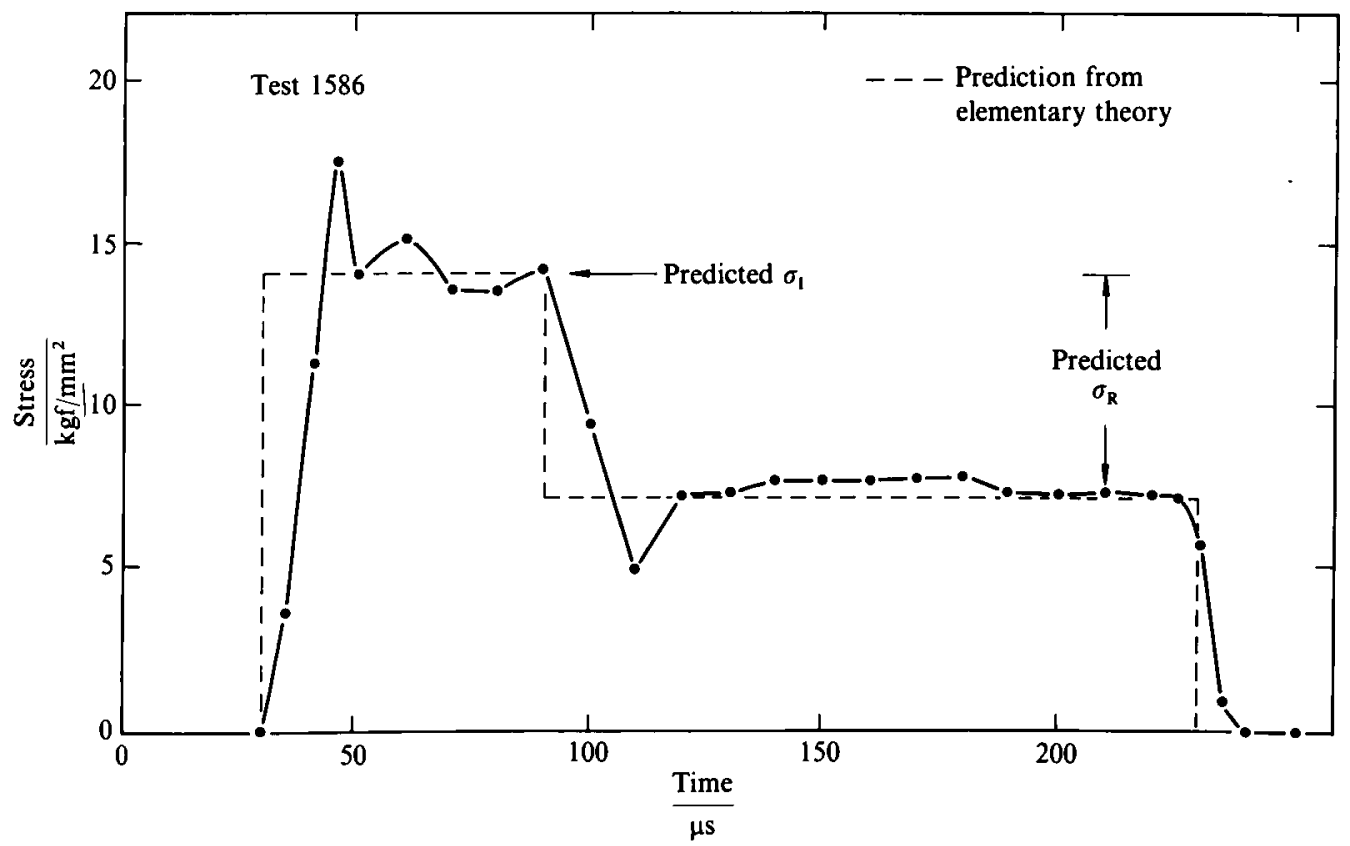

Fig. 7. Stress history of hard load-bar, measured at $15.24 \mathrm{~cm}$ from impact face using wire resistance gauges. Interface was glued and impact velocity was $9.86 \mathrm{~m} / \mathrm{s}$

strains due to the transmitted waves are given in Table 1. These predicted maximum strains are obtained from equation (19). For the strains that are recorded under test nos 1706, 1708, 1710 and 1712, the diffraction grating was located in the solid portion of the specimen, and therefore these are compressive strains. In all other tests, the grating was located in the tubular portion of the specimen, and therefore the measured strains are tensile.

\section{SUMMARY AND CONCLUSIONS}

It has been shown that an analysis using some simple boundary conditions, together with linear elastic wave theory in a hard load-bar and finite-amplitude wave theory in terms of an experimentally-determined parabolic response function in a soft specimen, predicts very closely the experimental results. The above conclusion is only true for a material with no (or negligible) strain-rate-dependent behaviour.

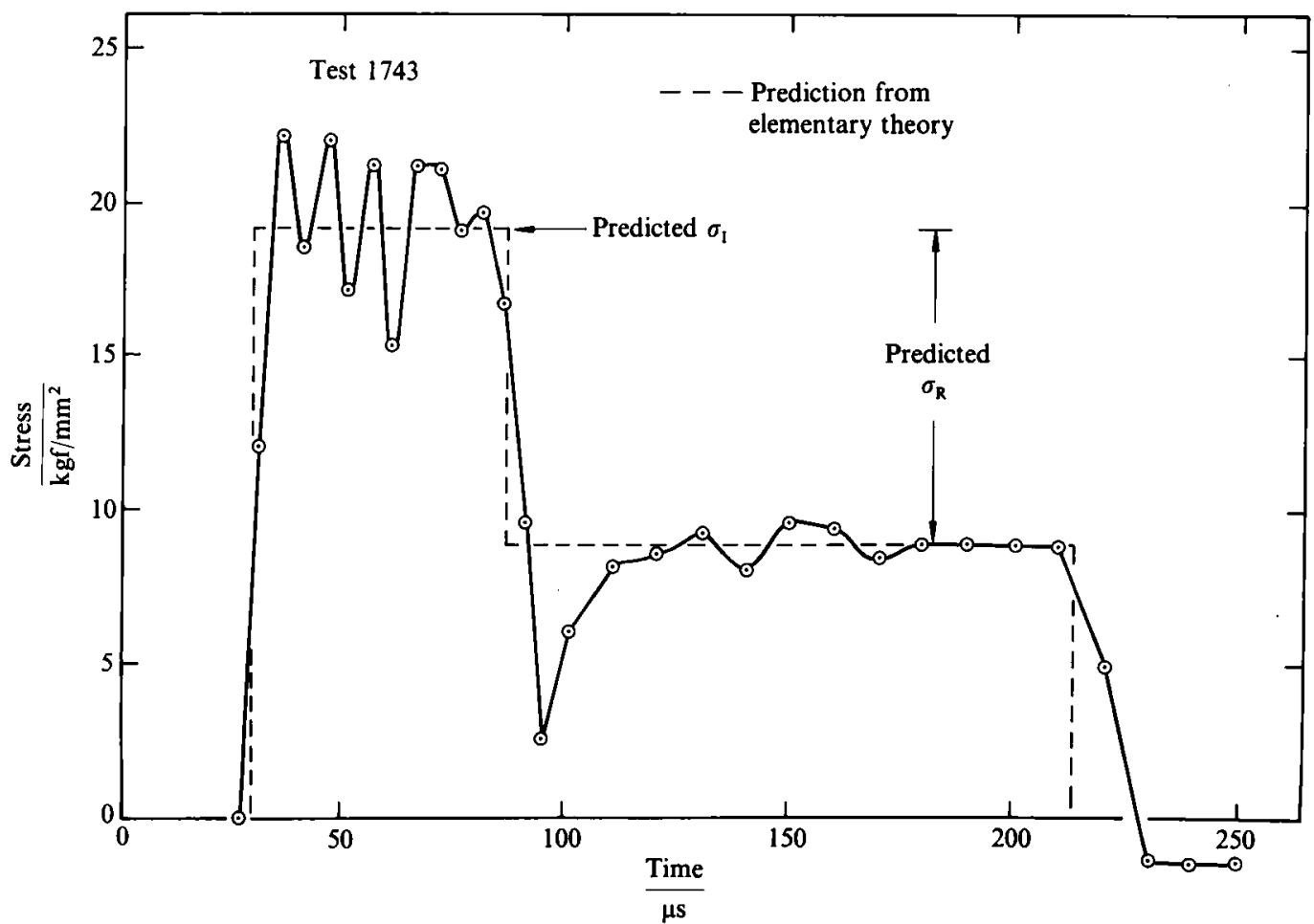

Fig. 8. Stress history of hard load-bar, measured at $15.24 \mathrm{~cm}$ from impact face using wire resistance gauges. In this case, load and striker bars were made of 7075-T6 aluminium. Impact velocity was $13.06 \mathrm{~m} / \mathrm{s}$ and interface was lubricated 


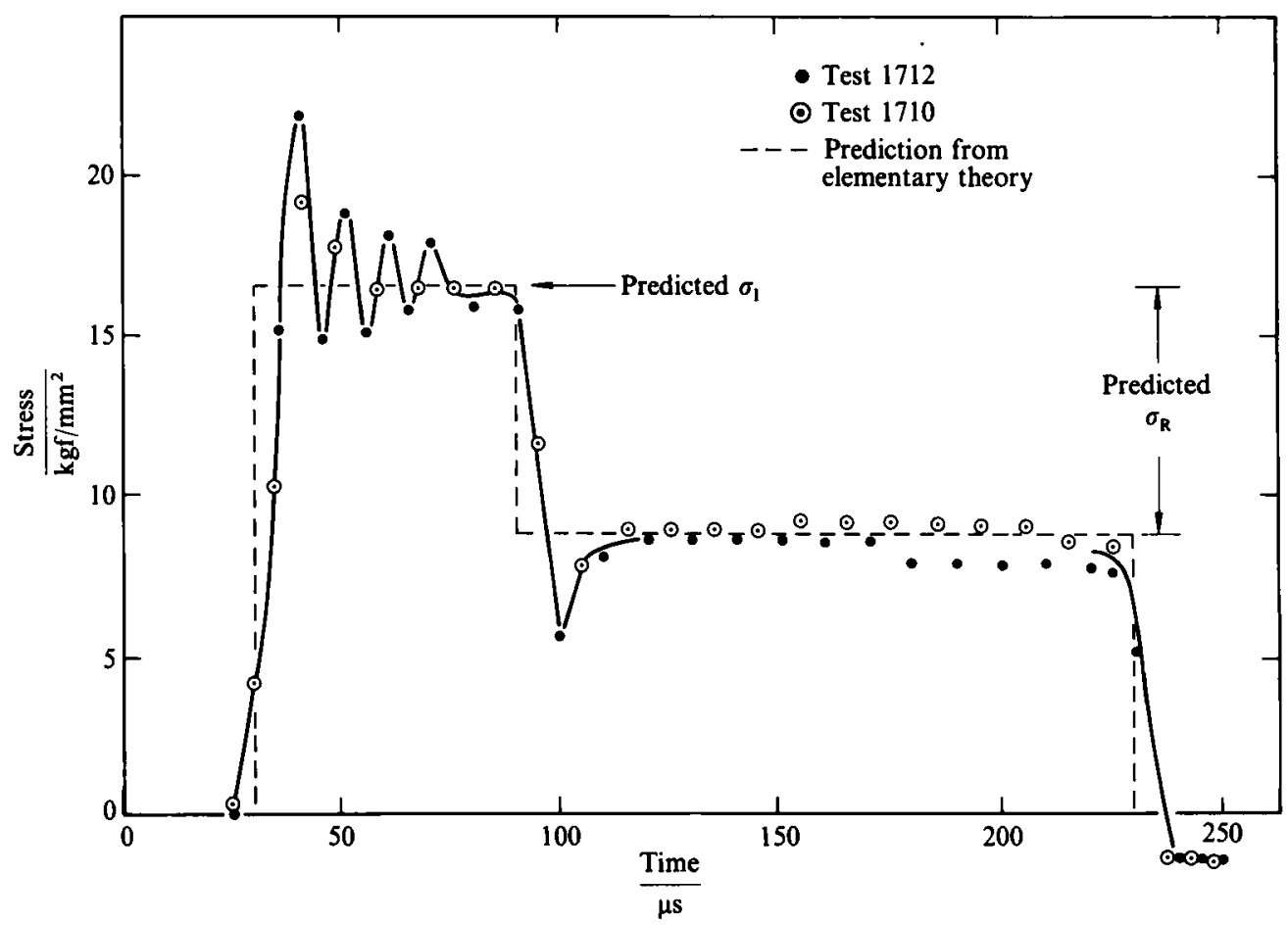

Fig. 9. Stress histories of hard load-bar, measured at $15.24 \mathrm{~cm}$ from impact face using wire resistance gauges. Impact velocities for tests 1710 and 1712 were 11.85 and $11.61 \mathrm{~m} / \mathrm{s}$, respectively. Interface was lubricated in each test.

Table 1. Comparison of predicted and observed maximum strains. The predicted values are obtained from Fig. 3. The gauge locations are given in the same order as the test numbers where these locations vary

\begin{tabular}{|c|c|c|c|c|c|c|c|}
\hline Test number & $\begin{array}{c}1651,1655 \\
\text { and } 1657\end{array}$ & $\begin{array}{c}1635,1636 \\
\text { and } 1640\end{array}$ & $\begin{array}{c}1613 \text { and } \\
1614\end{array}$ & $\begin{array}{c}1572,1586 \\
\text { and } 1593\end{array}$ & 1739 & $\begin{array}{l}1570 \text { and } \\
1743\end{array}$ & $\begin{array}{c}1706,1712, \\
1708 \text { and } \\
1710 \\
\end{array}$ \\
\hline Average impact velocity $(\mathrm{m} / \mathrm{s})$ & 11.34 & 11.33 & 11.26 & 10.01 & 9.72 & 13.15 & 11.67 \\
\hline $\begin{array}{l}\text { Distance of diffraction-grating } \\
\text { gauge in tubular }(\mathrm{T}) \text { or solid } \\
\text { (S) portion of specimen from } \\
\text { interface }(\mathrm{cm})\end{array}$ & $\begin{array}{l}5.08(\mathrm{~T}) \\
3.89(\mathrm{~T}) \\
1.51(\mathrm{~T})\end{array}$ & $1.43(\mathrm{~T})$ & $3.81(\mathrm{~T})$ & $3.81(T)$ & $4.92(\mathrm{~T})$ & $\begin{array}{l}3.81(\mathrm{~T}) \\
5.32(\mathrm{~T})\end{array}$ & $\begin{array}{l}5.08(S) \\
5.08(S) \\
7.62(S) \\
7.62(S)\end{array}$ \\
\hline Predicted $\varepsilon_{\max }$ & 0.0204 & 0.0205 & 0.0198 & 0.0165 & 0.0159 & 0.0252 & 0.0210 \\
\hline Observed $\varepsilon_{\max }$ & 0.0206 & 0.0209 & 0.0195 & 0.0165 & 0.0160 & 0.0258 & 0.0214 \\
\hline
\end{tabular}

\section{ACKNOWLEDGEMENTS}

The author is grateful to Prof. J. F. Bell for his many helpful suggestions. The typing of the manuscript by Mrs J. A. Christina is also gratefully acknowledged.

\section{APPENDIX}

\section{REFERENCES}

(1) TAYLOR, G. I. British Official Report, RC329 1942.

(2) KARMAN, T. V. NRDC Report A29, OSRD365 1942.
(3) WHITE, M. P. and GRIFFIS, L. V. NRDC Report A7, OSRD742 1942.

(4) J. F. BELL, 'Large deformation dynamic plasticity at an elasticplastic interface', J. mech. Phys. Solids 1968 16, 295-313.

(5) BELL, J. F. 'Determination of dynamic plastic strains through use of diffraction gratings', J. appl. Phys. 1956 27(10).

(6) BELL, J. F. 'Experimental foundations of solid mechanics', Handbuch der Physik 1973 VIa/1 (Springer-Verlag, Berlin).

(7) KHAN, A. S. 'A study of one-dimensionality and isochoric deformation during the passage of tensile waves', Experimental Mechanics 197414.

(8) KHAN, A. S. 'Behaviour of aluminium during the passage of large amplitude plastic waves', Int. J. mech. Sci. 1973 15, 503-516. 